\title{
Key features of mcr-1-bearing plasmids from Escherichia coli isolated from humans and food
}

\author{
Katrin Zurfluh ${ }^{1 *}$, Magdalena Nüesch-Inderbinen ${ }^{1}$, Jochen Klumpp ${ }^{2}$, Laurent Poirel ${ }^{3,4}$, Patrice Nordmann ${ }^{3,4}$
} and Roger Stephan ${ }^{1}$

\begin{abstract}
Background: Mcr-1-harboring Enterobacteriaceae are reported worldwide since their first discovery in 2015. However, a limited number of studies are available that compared full-length plasmid sequences of human and animal origins.

Methods: In this study, mcr-7-bearing plasmids from seven Escherichia coli isolates recovered from patients $(n=3)$, poultry meat $(n=2)$ and turkey meat $(n=2)$ in Switzerland were further analyzed and compared. Isolates were characterized by multilocus sequence typing (MLST). The mcr-7-bearing plasmids were transferred by transformation into reference strain E. coli DH5a and MCR-1-producing transformants were selected on LB-agar supplemented with $2 \mathrm{mg} / \mathrm{L}$ colistin. Purified plasmids were then sequenced and compared.

Results: MLST revealed six distinct STs, illustrating the high clonal diversity among mcr-1-positive E. coli isolates of different origins. Two different $m c r-1$-positive plasmids were identified from a single E. coli ST48 human isolate. All other isolates possessed a single mcr-1 harboring plasmid. Transferable Incl2 (size ca. 60-61 kb) and IncX4 (size ca. 33-35 kb) type plasmids each bearing mcr-1 were found associated with human and food isolates. None of the mcr-1-positive Incl2 and IncX4 plasmids possessed any additional resistance determinants. Surprisingly, all but one of the sequenced mcr-1-positive plasmids lacked the ISAp/1 element, which is a key element mediating acquisition of mcr-1 into various plasmid backbones.

Conclusions: There is strong evidence that the food chain may be an important transmission route for mcr-1bearing plasmids. Our data suggest that some "epidemic" plasmids rather than specific E. coli clones might be responsible for the spread of the $\mathrm{mcr}^{-1}$ gene along the food chain.
\end{abstract}

Keywords: Colistin, Mcr-1, Plasmid, ISAp/1

\section{Background}

The increasing number of multidrug-resistant Gramnegative bacteria and the lack of novel antimicrobials has led to the reintroduction of polymyxins as last-resort antimicrobials in human medicine, although once avoided because of its nephro- and neurotoxicity $[1,2]$. By contrast, in veterinary medicine, colistin is still widely used for the treatment of diarrhea in food-producing animals such as calves and pigs in most countries [3]. Until late

\footnotetext{
* Correspondence: katrin.zurfluh@uzh.ch

${ }^{1}$ Institute for Food Safety and Hygiene, Vetsuisse Faculty University of Zurich, Winterthurerstrasse 272, 8057 Zurich, Switzerland

Full list of author information is available at the end of the article
}

2015, only chromosomally-encoded mechanisms of resistance to polymyxins were known [4]. The mobile colistin resistance gene, $m c r-1$, was first described on a conjugative IncI2 plasmid from Chinese isolates. It encodes a phosphoethanolamine transferase that adds phosphoethanolamine to the lipid A [5]. Retrospective studies performed worldwide revealed that the gene had been circulating undetected for at least twenty years and animals have been suggested to be its main reservoir [6]. The dissemination of $m c r-1$ is associated with a large variety of plasmids including incompatibility groups IncI2, IncX4, IncF, IncHI1, IncHI2, IncP and IncY [7-10]. Most of these groups are well 
known to be involved in the spread of a diversity of antibiotic resistance genes in Enterobacteriaceae.

The aim of this study was to characterize $\mathrm{mcr}$-1-bearing plasmids from $E$. coli originating from humans and food isolated at the same location (Switzerland) in order to improve the understanding of the epidemiology and spreading potential of the $m c r-1$ gene.

\section{Methods}

In total, seven $E$. coli isolates harboring $m c r-1$ plasmids were used in the present study, including one uropathogenic E. coli (UPEC) isolate recovered from human urinary tract infection (CDF8), two isolates from humans with diarrhea and history of travel to Asia (ColR598 and ColR644SK1), and two isolates respectively from retail poultry meat (PC11 and PF11) and retail turkey meat (PF52 and PF91). UPEC strain CDF8 was obtained from a patient hospitalized in Switzerland in 2016 (unpublished) and food isolates PC11, PF11, PF52 and PF91 had been isolated in 2016 from food imported from Germany and sold in retail stores in Switzerland [11] ColR598 and ColR644SK1 were obtained from a stool sample screening from patients with diarrhea during the June to December 2016 period. Briefly, a total of 320 non-duplicate samples were screened for the presence of colistin-resistant Enterobacteriaceae by enriching one loopful of stool in $5 \mathrm{ml}$ Enterobacteriaceae enrichment (EE) broth (BD, Franklin Lakes, NJ, USA) for $24 \mathrm{~h}$ at $37{ }^{\circ} \mathrm{C}$, followed by streaking one loopful onto LB agar plates containing $4 \mathrm{mg} / \mathrm{L}$ colistin, $10 \mathrm{mg} / \mathrm{L}$ vancomycin and $5 \mathrm{mg} / \mathrm{L}$ amphotericin $\mathrm{B}$ for selection of colistinresistant Gram-negative bacteria. The isolates were identified using API ID 32 E (bioMérieux, Marcy l'Etoile, France) and analyzed for the presence of $m c r-1$ by PCR as described previously [5]. Minimal inhibitory concentration of colistin was determined for $m c r-1$-positive isolates using broth dilution tests as recommended by EUCAST. Moreover, isolates were subjected to susceptibility testing against 13 antimicrobial agents by the disc diffusion method according to CLSI protocols and evaluated according to CLSI criteria [12].

Multilocus sequence typing (MLST) was performed as described previously [13], and isolates were assigned to sequence types (ST) and clonal complexes (CC) according to the Achtman scheme (http://mlst.ucc.ie/ $\mathrm{mlst} / \mathrm{dbs} /$ Ecoli).

The $m c r$-1-positive plasmids were extracted using the Qiagen Midi kit (Qiagen, Hombrechtikon, Switzerland) and transferred by transformation using electroporation into $E$. coli $\mathrm{DH} 5 \alpha$. Colistin-resistant transformants were selected on LB-agar supplemented with $2 \mathrm{mg} / \mathrm{L}$ colistin (Sigma-Aldrich, Buchs SG, Switzerland). The mcr-1 plasmids were extracted using the Large-Construct Kit (Qiagen, Hombrechtikon, Switzerland) according the manufacturer's protocol and sequenced on a PacBio RS2 device (Pacific Biosciences, Menlo Park, USA) with a $10 \mathrm{~kb}$ size-selected insert library and P6/C4 chemistry. De novo assembly (using the HGAP3 algorithm) was performed using SMRTanalysis version 2.3.0 (Pacific Biosciences). The HGAP3 settings were kept at the defaults, except for the expected genome size, which was set between $50 \mathrm{~kb}$ and $100 \mathrm{~kb}$. The plasmid sequence was automatically annotated using the online Rapid Annotation Subsequencing Technology (RAST) [14] and CLC Main Workbench Version 7.8.1 (CLC bio, Aarhus, Denmark). Automated annotation was manually refined using the BLASTn and BLASTp programs (http://blast.ncbi.nlm.nih.gov/Blast.cgi).

\section{Results and discussion}

The results of this study analyzing seven distinct $\mathrm{mor}-1$ harbouring isolates of different sources are summarized in Table 1. Noticeably, all mor-1-harbouring isolates were $E$. coli that correspond to the most important reservoir of MCR-1 producers identified so far. MLST analysis did not show any close clonal relationship between the seven $m c r-1$-positive $E$. coli isolates, suggesting that the dissemination of the $m c r-1$ gene is so far not primarily associated with any specific clonal lineage.

From the seven E. coli isolates, a total of eight mcr-1bearing plasmids was recovered, with the human isolate ColR598 yielding two distinct $m c r-1$-positive plasmids. $\mathrm{Li}$ and colleagues showed in a recent study that coexistence of two $\mathrm{mcr}-1$ bearing plasmids seems to be common [15]. Nevertheless, the MIC's for colistin were not affected by the number of $m c r-1$ bearing plasmids present in one isolate [15]. The eight plasmids belonged to two plasmid types that have been often shown to be involved in the spread of $m c r-1$ [16]. Three IncI2 plasmids (pPC11, pCoR598_2 and pColR644SK1) were ca. $60 \mathrm{~kb}$ in-size, and were similar to pHNSHP45 (Fig. 1), the original sequenced $m c r-1$ plasmid published in 2015 [5]. The three IncI2 plasmids shared a common plasmid backbone, however, in the case of pPC11 the mcr- 1 cassette [17] was located in an inverted orientation compared to the others (data not shown). Additionally, the IncI2 plasmids from human isolates (pColR598_2 and pColR644SK1) varied greatly compared to the plasmid pPC11 (poultry isolate) in the shufflon region, which is a clustered inversion region encoding components of the pilV protein involved in plasmid transmission [18]. The components are rearranged by Rci, a recombinase encoded by the $r c i$ gene (Fig. 1). This observation is in accordance with recently sequenced IncI 2 plasmids carrying $m c r-1$ detected in E. coli from swine and cattle in Japan [19].

The other five plasmids (pPF11, pPF52, pPF91, pCDF8 and pColR598_1) all belonged to the plasmid incompatibility group IncX4 and were ca. $33 \mathrm{~kb}$ in-size. Their 
Table 1 Features of the eight mcr-1-harboring plasmids from seven E. coli isolated from humans and from food

\begin{tabular}{|c|c|c|c|c|c|c|c|c|c|c|c|}
\hline $\begin{array}{l}\text { Host } \\
\text { strain ID }\end{array}$ & Origin & Source & ST (CC) & $\begin{array}{l}\text { MIC colistin } \\
{[\mathrm{mg} / \mathrm{L}]}\end{array}$ & $\begin{array}{l}\text { Resistance } \\
\text { profile }\end{array}$ & $\begin{array}{l}\text { mcr-1 } \\
\text { harbouring } \\
\text { plasmid }\end{array}$ & $\begin{array}{l}\text { Plasmid } \\
\text { size (bp) }\end{array}$ & $\begin{array}{l}\text { Inc } \\
\text { group }\end{array}$ & $\begin{array}{l}\text { Mcr-1 } \\
\text { gene } \\
\text { cassette }\end{array}$ & $\begin{array}{l}\text { Additional resistance } \\
\text { genes on the } \mathrm{mcr-1} \\
\text { harbouring plasmid }\end{array}$ & Reference \\
\hline PC11 & Chicken & Meat & ST1251 & 8 & $\mathrm{AM}, \mathrm{CF}$ & pPC11 & 59.830 & Incl2 & ISAp/1-mcr-1-orf & none & [11] \\
\hline PF11 & Chicken & Meat & $\begin{array}{l}\text { ST156 } \\
\text { (CC156) }\end{array}$ & 8 & $\begin{array}{l}\mathrm{AM}, \mathrm{CF}, \mathrm{NA}, \\
\mathrm{CIP}, \mathrm{TE}\end{array}$ & pPF11 & 33.308 & $\operatorname{lncX} 4$ & mcr-1-orf & none & [11] \\
\hline PF52 & Turkey & Meat & $\begin{array}{l}\text { ST58 } \\
\text { (CC155) }\end{array}$ & 4 & $\mathrm{AM}, \mathrm{CF}, \mathrm{SMZ}$ & pPF52 & 33.300 & $\operatorname{lnc} X 4$ & mcr-1-orf & none & [11] \\
\hline PF91 & Turkey & Meat & ST1431 & 8 & $\begin{array}{l}\mathrm{AM}, \mathrm{CF}, \mathrm{TE}, \mathrm{C} \\
\mathrm{SMZ}\end{array}$ & pPF91 & 33.310 & $\operatorname{lnc} X 4$ & $m c r-1$-orf & none & [11] \\
\hline CDF8 & Human & UTI & nd & 4 & $\begin{array}{l}\text { AM, CZ, CTX, } \\
\text { FEP, NA, CIP, } \\
\text { S, K }\end{array}$ & pCDF8 & 33.660 & $\operatorname{lnc} X 4$ & $m c r-1-o r f$ & none & this study \\
\hline ColR598 & Human & Diarrhea & $\begin{array}{l}\text { ST48 } \\
\text { (CC10) }\end{array}$ & 4 & $N A, C I P, T E$ & pColR598_1 & 33.299 & $\operatorname{lnc} X 4$ & mcr-1-orf & none & this study \\
\hline ColR598 & Human & Diarrhea & $\begin{array}{l}\text { ST48 } \\
\text { (CC10) }\end{array}$ & 4 & $N A, C I P, T E$ & pColR598_2 & 60.939 & Incl2 & mcr-1-orf & none & this study \\
\hline ColR644SK1 & Human & Diarrhea & ST117 & 4 & $\begin{array}{l}\text { AM, CF, TE, } \\
\text { C, SMZ, TMP }\end{array}$ & pColR644SK1 & 60.952 & Incl2 & $m c r-1$-orf & none & this study \\
\hline
\end{tabular}

Abbreviations: CC clonal complex; Inc. plasmid incompatibility group; ST sequence type; UTI urinary tract infection, not determined; MIC minimal inhibitory concentration; $A M$ ampicillin; CF cephalothin; CZ cefazolin; CIP ciprofloxacin; NA nalidixic acid; K kanamycin; $S$ streptomycin; SMZ sulfamethoxazole; TMP trimethoprim; TE tetracycline; $C$ chloramphenicol

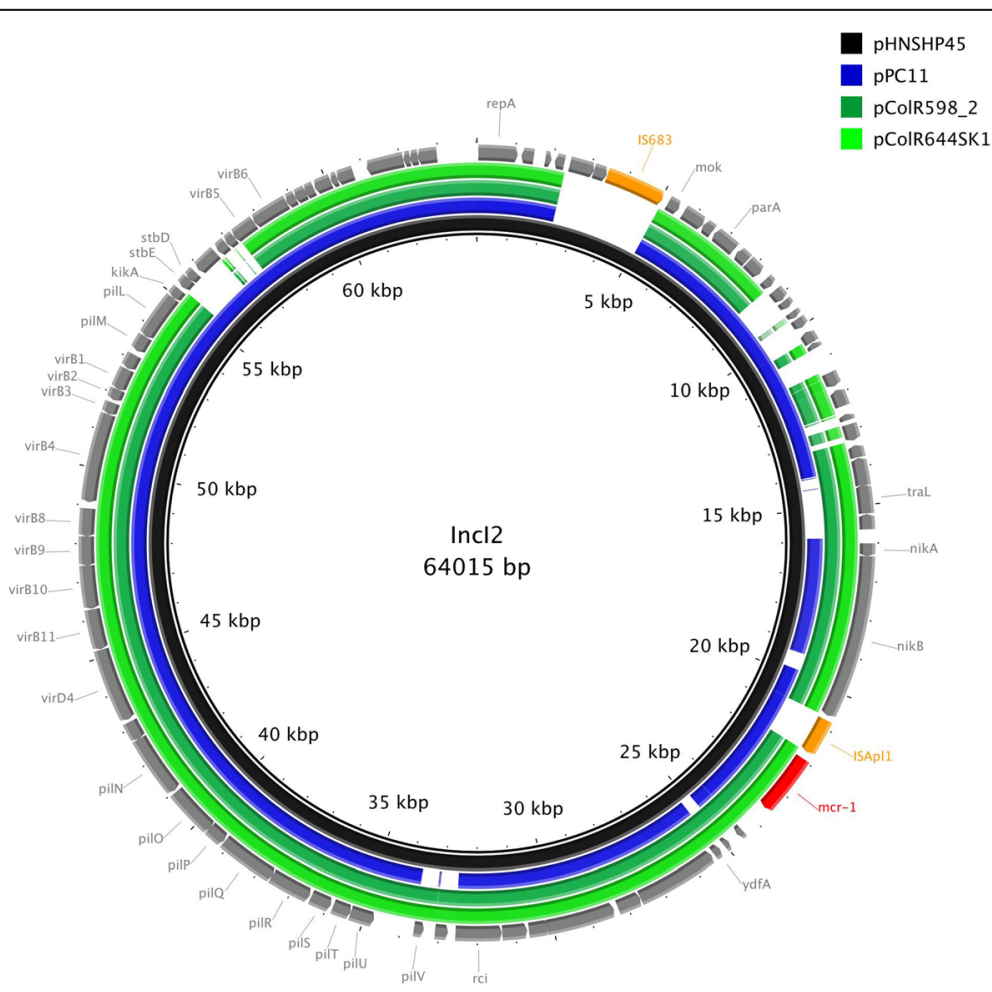

Fig. 1 Sequencing alignment of Incl2-type mcr-1-harboring plasmids. The first mcr-1-harboring plasmid, pHNSHP45 (Accession-Nr. KP347127), which was isolated in China, was used as reference plasmid (black circle). The outmost circle in grey arrows shows the annotations of the reference plasmid. The insertions element and the mar-1 gene were highlighted in orange and red arrows, respectively. Gaps indicate regions that were missing in the respective plasmid compared to the reference plasmid 
sequences varied only by very few nucleotides $(\geq 99 \%$ homology), mostly located in non-coding regions (Fig. 2). In the case of pDCF8 the $m c r-1$ cassette was located in an inverted orientation compared to the others (data not shown). Of note, those almost identical IncX4 plasmids originate from humans, poultry and turkey meat, illustrating their wide dissemination throughout multiple sources, and providing further evidence of the likely association of $\mathrm{mcr}$-1-mediated colistin resistance through food-producing animals.

An open reading frame (orf) encoding an hypothetical protein with similarities to a PAP2 superfamily protein was detected immediately downstream of the $m c r-1$ gene (both together hereafter referred to as $m c r-1$ cassette) was identified on all eight plasmids.

The insertion sequence ISApl1, has been shown to play a key role in the mobilization of $m c r-1$ [20], but was absent upstream of $m c r-1$ in most of our isolates. Further evidence for the importance of ISApl1 in the mobilization of $m c r-1$ was the presence of ISApl1 next to the $m c r-1$ gene on the chromosome of an E. coli veal calf isolate from Netherland [21]. Moreover, transposition of the mcr-1 gene by an ISApl1-made composite transposon was recently demonstrated [17]. Highly similar inverted repeat (IRR) and direct repeat (DR) sequences were identified on IncX4, IncHI1 and IncHI2 backbones immediately downstream of the mcr-1 cassette, resembling the target insertion site resulting from the ISApl1-mediated transposition [16], although the IS element itself was not always present. In a recent study, no putative inverted repeat sequences were identified at the extremities of the $m c r-1$ cassette [22]. Furthermore, Snesrud and colleagues [20] proposed the loss of one or both ISApl1 elements as an explanation for the minor variations (mismatches and deletions) at the 3'end of the mor-1 element. Accordingly, in this study, ISApl1 was present only on a single IncI2 plasmid (pPC11) and was located upstream of the $m c r-1$ gene.

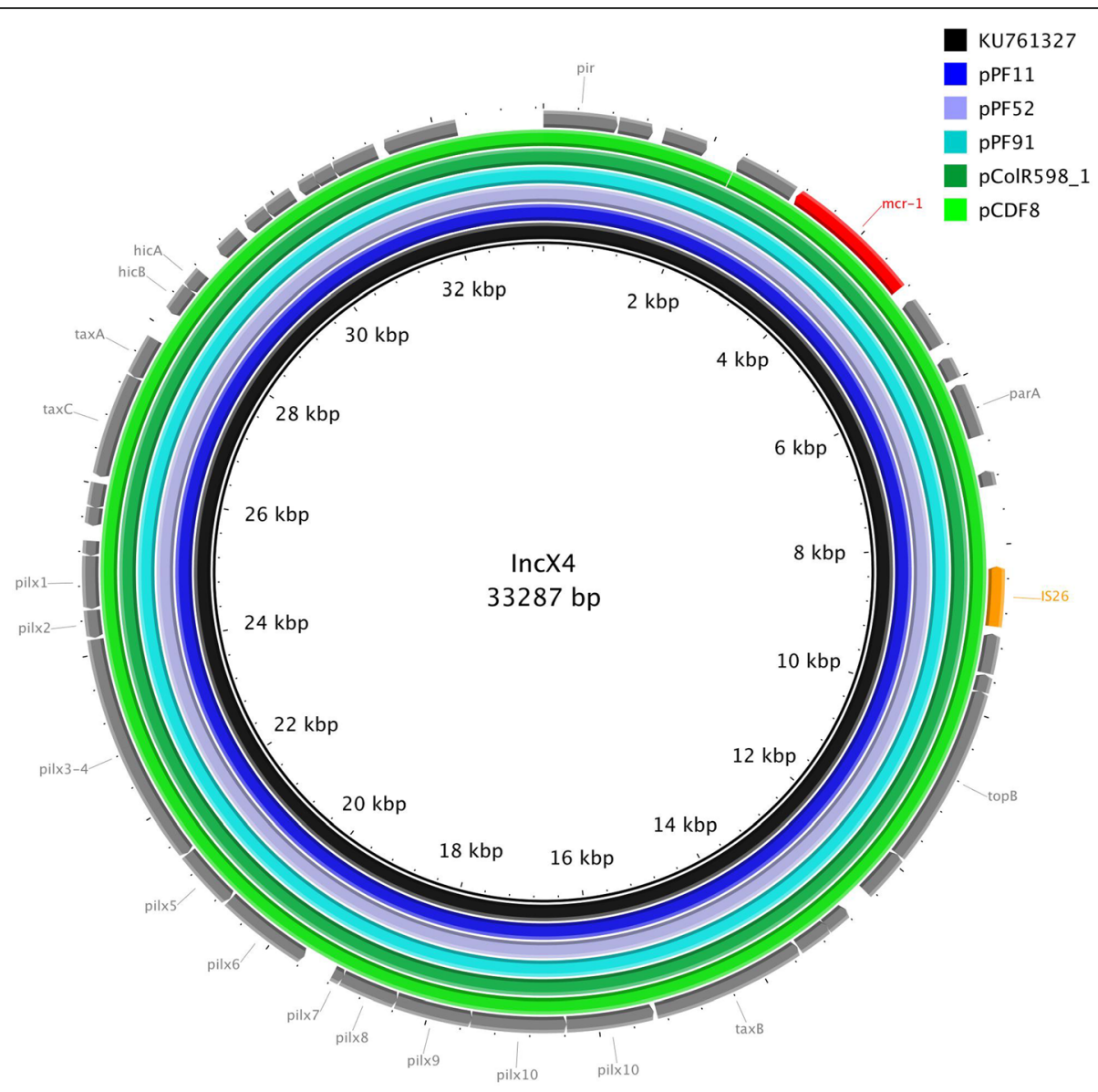

Fig. 2 Sequencing alignment of IncX4-type mcr-1-harboring plasmids. The mcr-1 harboring plasmid, pmcr-1_X4 (Accession-Nr. KU761327), which was obtained from two Klebisiella pneumonia isolates and one Escherichia coli isolate from patients in eastern China and which was one of the first sequenced IncX4 mcr-1 positive plasmids, was used as reference plasmid (black circle). The outmost circle in grey arrows shows the annotations of the reference plasmid. The insertions element and the $m c r-1$ gene were highlighted in orange and red arrows, respectively. The figure indicates the high degree of homology of the mcr-1 harboring IncX4 plasmids independently of their isolation source and geographical origin 
Noticeably, none of the sequenced plasmids carried additional antibiotic resistance determinants. This is in agreement with other observations $[5,9,22]$ and appears to be quite a specificity to the $m c r-1$ gene, considering that most antibiotic resistance plasmids often carry multiple resistance genes. It is therefore tempting to speculate that this specificity is related to selection of those MCR-1 determinants by treatment containing polymyxins in animals. Moreover, the food samples described in this study originated from Germany, a country with high use of colistin in animal husbandry, and both humans with diarrhea had visited countries in Asia, where colistin is applied widely to treat animals [3]. However, the extended-spectrum $\beta$ lactamase gene $b l a_{\text {СTX-M-64 }}$ has recently been detected on an $m c r-1$-harboring IncI2 plasmid [23]. There are some further data were the $m c r-1$ gene was located on large multidrug resistance plasmids for example in combination with extended-spectrum beta-lactamase genes $[9,15,24]$. In these studies $m c r-1$ was mainly harboured on IncHI2 or IncF plasmids. It is to be expected that $m c r-1$ harboring plasmids co-harboring resistances to antimicrobials crucial to human treatment become more frequent in future.

\section{Conclusion}

Transferable IncI2 and IncX4 type plasmids harbouring $m c r-1$ were found in E. coli of different clonal backgrounds isolated from humans and from food. The high similarity between the plasmids belonging to the same incompatibility groups shows that these "epidemic" plasmids may be responsible for the spread of the $\mathrm{mcr}-1$ gene along the food chain and humans, rather than single specific $E$. coli clones. A single strain may even contain more than one $m c r-1$-harboring plasmid. Further studies are needed in order to determine the mechanisms that lead to the acquisition or even accumulation of mcr-1-harboring plasmids within Enterobacteriaceae.

\section{Abbreviations}

bla: B-lactamase gene; CC: Clonal complex; EE: Enterobacteriaceae enrichment; Inc: Plasmid incompatibility group; MLST: Multilocus sequence type; NENT: National Centre for Enteropathogenic Bacteria and Listeria; ST: Sequence type; UPEC: Uropathogenic E. coli; UTI: Urinary tract infection

\section{Acknowledgements}

We are grateful to the staff of the Functional Genomics Center Zurich, particularly Simon Grüter and Andrea Patrignani for excellent technical support and bioinformatics support.

\section{Funding}

This work was funded by the Swiss Federal Office of Public Health, Division Communicable Diseases.

\section{Availability of data and materials}

The GenBank accession numbers for pPF91, pPF52, pPF11, pPC11, pColR644SK1, pColR598_2, pColR598_1 and pCDF8 are MF175184, MF175185, MF175186, MF175187, MF175188, MF175189, MF175190 and MF175191 respectively.

\section{Authors' contributions}

RS, LP and PN designed the study. KZ carried out the microbiological and molecular biological tests. KZ and JK did the bioinformatic analysis. KZ, MNI and RS analyzed and interpreted the data. KZ and MNI drafted the manuscript. All authors read and approved the final manuscript.

\section{Ethics approval and consent to participate}

All procedures performed in studies involving human participants were in accordance with the ethical standards of the institutional and/or national research committee and with the 1964 Helsinki declaration and its later amendments or comparable ethical standards. This type of study is approved by the local ethics committee of Zürich (BASEC-Nr. Req-2016-00374).

Consent for publication

Not applicable.

\section{Competing interests}

The authors declare that they have no competing interest.

\section{Publisher's Note}

Springer Nature remains neutral with regard to jurisdictional claims in published maps and institutional affiliations.

\section{Author details}

${ }^{1}$ Institute for Food Safety and Hygiene, Vetsuisse Faculty University of Zurich, Winterthurerstrasse 272, 8057 Zurich, Switzerland. ${ }^{2}$ Institute of Food, Nutrition and Health, ETH Zurich, Schmelzbergstr. 7, 8092 Zurich, Switzerland.

${ }^{3}$ Emerging Antibiotic Resistance, Medical and Molecular Microbiology Unit, Department of Medicine, University of Fribourg, Fribourg, Switzerland.

${ }^{4}$ National Reference Center for Emerging Antibiotic Resistance, University of Fribourg, Fribourg, Switzerland.

Received: 12 June 2017 Accepted: 25 August 2017

Published online: 06 September 2017

\section{References}

1. Paterson DL, Harris PNA. Colistin resistance: a major breach in our last line of defense. Lancet Infect Dis. 2016;16:132-3.

2. Poirel L, Jayol A, Nordmann P. Polymyxins: antibacterial activity, susceptibility testing and resistance mechanisms encoded by plasmids or chromosomes. Clin Microbiol Rev. 2017;30:557-96.

3. Irrgang A, Roschanski N, Tenhagen B-A, Grobbel M, Skladnikiewicz-Ziemer T, Thomas K, et al. Prevalence of mcr-1 in E. coli from livestock and food in Germany, 2010-2015. PLoS One. doi: 10.1371/journal.pone.0159863.

4. Olaitan $\mathrm{AO}$, Morand $\mathrm{S}$, Rolain JM. Mechanisms of polymyxin resistance: acquired and intrinsic resistance in bacteria. Front Microbiol. 2014;5:1-18.

5. Liu YY, Wang Y, Walsh TR, Yi LX, Zhang R, Spencer J, et al. Emergence of plasmid-mediated colistin resistance mechanism MCR-1 in animals and human beings in China: a microbiological and molecular biological study. Lancet Infect Dis. 2015;16:161-8.

6. Schwarz S, Johnson AP. Transferable resistance to colistin: a new but old threat. J Antimicrob Chemother. 2016;71:2066-70.

7. Zhi C, Lv L, Yu LF, Doi Y, Liu JH. Dissemination of the mcr-1 colistin resistance gene. Lancet Infect Dis. 2016;16:292-3.

8. McGann P, Snesrud E, Maybank R, Corey B, Ong AC, Clifford R, et al. Escherichia coli harboring mcr-1 and bla $a_{\mathrm{CX}-\mathrm{M}}$ on a novel IncF plasmid: first report of mcr-1 in the USA. Antimicrob Agents Chemother. 2016;60:4420-1.

9. Zurfluh K, Klumpp J, Nüesch-Inderbinen M, Stephan R. Full-length nucleotide sequences of $\mathrm{mcr}-1$-harboring plasmids isolated from extendedspectrum- $\beta$-lactamase-producing Escherichia coli isolates of different origins. Antimicrob Agents Chemother. 2016;60:5589-91.

10. Zhang C, Feng Y, Liu F, Jiang H, Qu Z, Lei M, et al. Phage-like IncY plasmid carrying the $\mathrm{mcr}^{-1}$ gene in Escherichia coli from a pig farm in China. Antimicrob Agents Chemother. 2016; doi: 10.1128/AAC.02035-16.

11. Zurfluh K, Buess S, Stephan R, Nüesch-Inderbinen M. Assessment of the occurrence of MCR producing Enterobacteriaceae in Swiss and imported poultry meat. J Food Sci Tech. 2016; doi: 10.15436/JFST.1.4.5.

12. Clinical and Laboratory Standards Institute. 2016. M100S. Performance standards for antimicrobial susceptibility testing, $26^{\text {st }}$ informational supplement. Clinical and Laboratory Standards Institute, Wayne, PA. 
13. Wirth T, Falush D, Lan R, Colles F, Mensa P, Wieler LH, et al. Sex and virulence in Escherichia coli: an evolutionary perspective. Mol Microbiol. 2006;60:1136-51. doi: 10.1111/j.1365-2958.2006.05172.x.

14. Aziz RK, Bartels D, Best AA, DeJongh M, Disz T, Edwards RA, et al. The RAST server: rapid annotations using subsystems technology. BMC Genomics. 2008; doi: 10.1186/1471-2164-9-75.

15. Li R, Xie M, Zhang J, Yang Z, Liu L, Liu X, et al. Genetic characterization of mcr-1-bearing plasmids to depict molecular mechanisms underlying deissemination of the colistin resistance determinant. J Antimicrob Chemother. 2017;72:393-401

16. Sun J, Fang L-X, Zuowei W, Deng H, Yang R-S, Li X-P, et al. Genetic analysis of the IncX4 plasmids: implications for a unique pattern in the mcr-1 acquisition. Sci Rep. 2017;7:424

17. Poirel L, Kieffer N., Nordmann P. In vitro study of ISApa1 mobilization of the colistin resistance gene mcr-1. Antimicrob Agents Chemother. 2017 pii: AAC. 00127-17. doi: 10.1128/AAC.00127-17.

18. Gyohda A, Furuya N, Kogure N, Komano T. Sequence-specific and nonspecific binding of the Rci protein to the asymmetric recombination sites of the R64 shuffflon. J Mol Biol. 2002;318:975-83.

19. Sekizuka T, Kawanishi M, Ohnishi M, Shima A, Kato K, Yamashita A, et al. Elucidation of quantitative structural diversity of remarkable rearrangement regions, shufflons, in Incl2 plasmids. Sci Rep. 2017;7:928.

20. Snesrud E, He S, Chandler M, Dekker JP, Hickmann AB, McGann P, Dyda F. A model for transposition of the colistin resistance gene $\mathrm{mcr}-1$ by ISAp/1. Antimicrob Agents Chemother. 2016;60:6973-6.

21. Veldman K, van Essen-Zandbergen A, Rapallini M, Wit B, Heymans R, van Pelt W, et al. Location of colistin resistance gene $m c r-1$ in Enterobacteriaceae from livestock and meat. J Antimicrob Chemother. 2017;71:2340-2.

22. Poirel L, Kieffer N, Brink A, Coetze J, Jayol A, Nordmann P. Genetic features of MCR-1-producing colistin-resistant Escherichia coli isolates in South Africa. Antimicrob Agents Chemother. 2016;60:4394-7. doi: 10.1128/AAC.00444-16.

23. Sonnevend A, Ghazawi A, Alqahtani M, Shibl A, Jamal W, Hashmey R, Pal T. Plasmid-mediated colistin resistance in Escherichia coli from the Arabian peninsula. Int J Infect Dis. 2016;50:85-90. doi: 10.1016/j.jijid.2016.07.007.

24. McGann P, Snesrud E, Maybank R, Corey B, Ong AC, Clifford R, et al. Escherichia coli harboring $\mathrm{mcr}_{\mathrm{C}-1}$ and blactx-M on a novel IncF plasmid: first report of $\mathrm{mcr}-1$ in the United States. Antimicrob Agents Chemother. 2016; 60:4420-1. doi: 10.1128/AAC.01103-16.

\section{Submit your next manuscript to BioMed Central and we will help you at every step:}

- We accept pre-submission inquiries

- Our selector tool helps you to find the most relevant journal

- We provide round the clock customer support

- Convenient online submission

- Thorough peer review

- Inclusion in PubMed and all major indexing services

- Maximum visibility for your research

Submit your manuscript at www.biomedcentral.com/submit

) Biomed Central 